\title{
Evidence for the Involvement of Apoptosis-Inducing Factor-Mediated Caspase-Independent Neuronal Death in Alzheimer Disease
}

\author{
Wenfeng Yu, ${ }^{*}$ Naguib Mechawar, ${ }^{*}$ \\ Slavica Krantic, ${ }^{\dagger}$ and Rémi Quirion* \\ From the Douglas Mental Health University Institute, Department \\ of Psychiatry," McGill University, Montréal, Quebec, Canada; \\ and the Institut de Neurobiologie de la Méditerranée, ${ }^{\dagger}$ INSERM \\ U29, Luminy, Marseille, France
}

\begin{abstract}
Accumulating evidence suggests the involvement of caspase-dependent and -independent mechanisms in neuronal cell death in Alzheimer disease (AD). The apoptosis-inducing factor (AIF) is a mitochondrial oxido-reductase originally characterized as a mediator of caspase-independent programmed cell death (PCD). In this postmortem study, we investigated the distribution of AIF and its possible morphological association with pathological features in the hippocampus, as well as entorhinal and medial gyrus of temporal cortices of late stage $\mathrm{AD}$, dementia with Lewy bodies (DLB), and control subjects. In comparison with controls, a significant increase in neuronal AIF immunoreactivity (AIF-ir) was observed in the hippocampus and the superficial layers of entorhinal and medial gyrus of temporal cortices in $\mathrm{AD}$ - but not DLB - samples. AIF-ir in neuronal nuclei was also significantly more widespread in AD compared with control and DLB samples. Furthermore, AIF-ir was found to be colocalized with neurofibrillary tangles (NFTs) in AD brains. Interestingly, a significant positive correlation was seen between nuclear AIF-ir and Braak stage in CA1 of the hippocampus as well as in entorhinal and temporal cortices in AD samples. These data show for the first time: (1) the nuclear localization of AIF in the AD brain and (2) its colocalization with NFTs, suggesting a possible involvement of AIF-mediated caspase-independent PCD, at least in the late stage of this neuropathology. (Am J Pathol 2010, 176:2209-2218; DOI: 10.2353/ajpath.2010.090496)
\end{abstract}

Programmed cell death (PCD) is thought to contribute significantly to neuronal cell loss in Alzheimer disease
(AD). ${ }^{1,2}$ Various caspases have been recognized as important mediators of neuronal PCD in AD. ${ }^{3}$ Several studies have shown the presence of activated caspases and the resulting caspase-cleaved substrates, including actin, tau, and amyloid precursor protein (APP) in AD brains and animal models. ${ }^{4-10}$ However, accumulating evidence also points to the involvement of caspase-independent mechanisms in neuronal PCD. ${ }^{11-13}$ Among the main players involved in caspase-independent neuronal cell death, apoptosis-inducing factor (AIF) has recently attracted much attention as a putative caspase-independent effector. ${ }^{14-16}$

AIF is a ubiquitously expressed flavoprotein and is synthesized as a cytoplasmic 67-kDa precursor, followed by its cleavage to a $62-k D a$ mature protein. This protein is then translocated into mitochondrial intermembrane space and embedded into the inner mitochondrial membrane. ${ }^{15,17}$ Under normal physiological conditions, AIF remains confined to the mitochondrial intermembrane space where it is involved in oxydo-reduction and handling the respiration-associated free radical production by their scavenging. ${ }^{12,15,18,19}$ On pathological permeabilization of the outer mitochondrial membrane, mature AIF is further processed to a $57-\mathrm{kDa}$ form by activated calpains and/or cathepsins. ${ }^{17,20,21}$ This AIF form is translocated to the nucleus and causes high-molecular-weight DNA fragmentation and chromatin condensation in a caspase-independent manner. ${ }^{15,22}$ Interestingly, both mitochondrial and nuclear effects of AIF have been observed in neuronal death associated with rodent aging and acute traumatic injuries. ${ }^{19,23}$ However, very few studies on AlF's implication in normal human brain aging or AD-associated

Supported by a grant from Canadian Institutes of Health Research (CIHR) to R.Q. and joint INSERM/FRSQ cooperation program to S.K. (France) and R.Q. (Québec). W.Y. is supported by a Fonds de la recherche en santé du Québec (FRSQ) fellowship. N.M. is a FRSQ scholar.

Accepted for publication December 24, 2009.

Supplemental material for this article can be found on http://ajp. amjpathol.org.

Address reprint requests to Rémi Quirion, Ph.D., Douglas Mental Health University Institute, McGill University, 6875 LaSalle Blvd., Montréal, QC Canada, H4H 1R3. E-mail: remi.quirion@douglas.mcgill.ca. 
neurodegeneration have been reported thus far. We recently reported the apparent lack of a significant difference in AIF protein levels in the tissue homogenates obtained from cortex and hippocampus of $A D$ versus age-matched control brains. ${ }^{24}$ However, the cellular distribution of AIF and its possible morphological association with neuropathological features (amyloid plaques and neurofibrillary tangles [NFTs]) in the AD brain remains to be investigated. Interestingly, previous studies have localized activated caspases within NFTs and neurites in AD brain regions rich in amyloid plaques. ${ }^{9,10}$

The aim of the present study was to study the cellular and subcellular distributions of AIF in the hippocampus, entorhinal, and medial temporal cortices in postmortem samples of late stage AD patients. Given that neuronal loss also occurs in the hippocampus of dementia with Lewy bodies (DLB), ${ }^{25}$ we also performed the same experiments with DLB samples to generate comparative data between these two progressive neurodegenerative disorders.

\section{Materials and Methods}

\section{Antibodies and Reagents}

Rabbit polyclonal antibody against the $\mathrm{C}$ terminus of human AIF (amino acids 593-613), mouse monoclonal antihuman $\beta$-amyloid (A $\beta$ ) antibody (Clone 4G8), and Cellytic NuCLEAR Extraction Kit were purchased from Sigma (St Louis, MO). Mouse monoclonal Anti-PHF-tau (paired helical filament tau) antibody (Clone AT8) was purchased from Fisher Canada (Nepean, ON, Canada). Mouse monoclonal anti-NeuN (Neuronal nuclei) antibody was purchased from Millpore (Billerica, MA). Rabbit polyclonal anti-GAPDH antibody and agarose-conjugated protein $G$ were obtained from Santa Cruz Biotechnology (Santa Cruz, CA).

\section{Human Brain Samples}

All experiments were approved by the Douglas Hospital Research Ethics Board. We studied brain samples from 10 cases of neuropathologically confirmed sporadic AD, 19 cases of age-matched controls, and 8 cases of DLB. Tissues were obtained from the Quebec Brain Bank (QBB; Douglas Institute, Montréal, QC, Canada). On arrival at the QBB, brains were divided midsagittally: the left hemisphere was cut into thick sections, which were flashfrozen and stored at $-80^{\circ} \mathrm{C}$ until use. The right hemisphere was fixed in formalin and examined by a neuropathologist for diagnostic purposes. Hippocampal and temporal cortical samples from all cases were also stained for amyloid plaques and NFTs (see below) and assessed for blind Braak staging by one of us (W.Y.), according to established criteria. ${ }^{26}$ Summary case information, including age, gender, postmortem interval (PMI), and Braak staging are presented in Table 1. The AD cases were selected by the neuropathologist on the basis of a diagnosis according to the CERAD criteria with a Braak amyloid plaque stage of $\mathrm{C}$ and a Braak tangle stage between II and VI. ${ }^{27}$ In tandem with the neuropathological reports, Braak staging allowed us to divide the controls into two groups: (1) Controls, which had no history of dementia and no neuropathological abnormalities, including a complete absence of amyloid plaques and NFTs, and (2) "controls with low AD pathology," which presented plaques and tangles with varying degrees, which remained below the threshold for AD diagnosis (Table 1). The latter had no history of dementia, a Braak amyloid plaque stage of A or less, and a Braak tangle stage of II or less, with no other neuropathological abnormalities. The DLB cases were identified by the neuropathologist using consensus DLB diagnostic criteria based on cortical scores of Lewy bodies counts of neocortical stained with $\alpha$-synuclein immunohistochemistry. ${ }^{28,29}$

For immunohistochemistry and image analysis, fixed paraffin-embedded tissues from the hipppcampus, entorhinal cortex, and medial gyrus of the temporal cortex were used. Frozen brain tissues of the hippocampus and the temporal cortex from the same subjects were used for the biochemical fractionation, Western blotting, and immunoprecipitation assays.

\section{Characterization of the AIF Antibody}

Rabbit polyclonal antibody against the $\mathrm{C}$ terminus of human AIF was characterized in normal human brain by Western blotting. Briefly, cytoplasmic fractions of human brain extracts were resolved through $4 \%$ to $20 \%$ TrisGlycine gels (Invitrogen, Burlington, ON, Canada) and transferred to nitrocellulose membranes. Membranes were incubated with the anti-AIF antibody $(1: 3000)$ at $4^{\circ} \mathrm{C}$ overnight, followed by incubation with horseradish peroxidase (HRP)-conjugated secondary antibody (Santa Cruz Biotechlogy) and processed with the ECL Plus chemiluminescence system (Fisher Canada). All three major AIF forms (67-kDa precursor, 62-kDa mitochondria-embedded, and 57-kDa mitochondria-released) were systematically detected (see supplemental Figure 1 at http://ajp. amjpathol.org) in the same pattern as previously reported in rat and human brain extracts obtained with a different goat polyclonal anti-AIF antibody (D-20, Santa Cruz Biotechnology). ${ }^{24}$

\section{AlF Immunocytochemistry and Double-Labeling Immunocytochemistry}

Immunohistochemical staining was performed on formalin-fixed paraffin-embedded sections as described previously. ${ }^{30}$ Sections were deparaffinized and rinsed in Tris-NaCl buffer (TBS) $(0.05 \mathrm{~mol} / \mathrm{L}$ Tris, $0.15 \mathrm{~mol} / \mathrm{L} \mathrm{NaCl}$, $\mathrm{pH}$ 7.6) and then treated with $1 \%$ hydrogen peroxide (30 minutes) to quench endogenous peroxidase activity. For antigen retrieval, sections were boiled in $0.05 \mathrm{~mol} / \mathrm{L}$ citrate-buffered saline ( $\mathrm{pH}$ 6.0). Sections were then blocked for an hour in $10 \%$ goat serum and incubated with the primary antibodies, anti-AIF (1:1000), or anti-NeuN (1:500) overnight (14 to 18 hours) at $4^{\circ} \mathrm{C}$. After a thorough rinse in TBS, sections were incubated with biotinylated secondary antibodies (Vector Laboratories, Burlingame, CA) for 60 minutes at room temperature. Staining was developed using avidin-biotin complex and DAB (Vector Laboratories) according to the manufacturer's instructions. 
Table 1. Summary of Cases Examined in the Present study

\begin{tabular}{|c|c|c|c|c|c|c|}
\hline & $\begin{array}{l}\text { Age } \\
\text { (years) }\end{array}$ & Sex & $\begin{array}{c}\text { PMI } \\
\text { (hours) }\end{array}$ & $\begin{array}{l}\text { Braak stage, } \\
\text { according to } A \beta^{\star}\end{array}$ & $\begin{array}{l}\text { Braak stage, according } \\
\text { to taupathology }{ }^{\dagger}\end{array}$ & DLB type \\
\hline \multicolumn{7}{|c|}{ Control $(n=11)$} \\
\hline $\mathrm{C} 1$ & 81 & $\mathrm{~F}$ & 27 & 0 & 0 & No LB disease \\
\hline $\mathrm{C} 2$ & 72 & $\mathrm{~F}$ & 13.5 & 0 & 0 & No LB disease \\
\hline $\mathrm{C} 3$ & 60 & $\mathrm{M}$ & 7.25 & 0 & 0 & No LB disease \\
\hline C4 & 92 & M & 22.5 & 0 & 0 & No LB disease \\
\hline C5 & 90 & $\mathrm{~F}$ & 13.5 & 0 & 0 & No LB disease \\
\hline C6 & 70 & $\mathrm{M}$ & 32.75 & 0 & 0 & No LB disease \\
\hline $\mathrm{C} 7$ & 71 & $\mathrm{~F}$ & 13.5 & 0 & 0 & No LB disease \\
\hline C8 & 76 & M & 11 & 0 & 0 & No LB disease \\
\hline $\mathrm{C9}$ & 77 & $\mathrm{~F}$ & 7 & 0 & 0 & No LB disease \\
\hline C10 & 83 & $\mathrm{M}$ & 6.75 & 0 & 0 & No LB disease \\
\hline C11 & 80 & M & 13.75 & 0 & 0 & No LB disease \\
\hline Mean & 77.4 & & 15.0 & & & \\
\hline SEM & 3.1 & & 3.1 & & & \\
\hline \multicolumn{7}{|c|}{ Controls (AD pathology; $n=8$ ) } \\
\hline C1 & 69 & $\mathrm{~F}$ & 8 & $A$ & I & No LB disease \\
\hline $\mathrm{C} 2$ & 74 & $\mathrm{~F}$ & 11 & $A$ & I & No LB disease \\
\hline C3 & 86 & $\mathrm{~F}$ & 5.75 & A & 1 & No LB disease \\
\hline $\mathrm{C} 4 \mathrm{I}$ & 77 & $\mathrm{~F}$ & 24.75 & $A$ & I & No LB disease \\
\hline $\mathrm{C} 5$ & 69 & M & 12 & $A$ & I & No LB disease \\
\hline C6 & 85 & M & 5.75 & A & i & No LB disease \\
\hline $\mathrm{C7}$ & 68 & M & 23.5 & A & I & No LB disease \\
\hline $\mathrm{C} 8$ & 75 & $\mathrm{~F}$ & 6.75 & A & II & No LB disease \\
\hline Mean & 75.4 & & 13.6 & & & \\
\hline SEM & 2.3 & & 2.7 & & & \\
\hline \multicolumn{7}{|c|}{$\operatorname{AD}(n=10)$} \\
\hline AD1 & 80 & $\mathrm{~F}$ & 24 & C & II & No LB disease \\
\hline AD2 & 78 & $\mathrm{~F}$ & 16 & C & III & No LB disease \\
\hline AD3 & 74 & $\mathrm{~F}$ & 7.5 & $\mathrm{C}$ & IV & No LB disease \\
\hline AD4 & 79 & $\mathrm{~F}$ & 10.8 & C & IV & No LB disease \\
\hline AD5 & 92 & M & 13.2 & C & VI & No LB disease \\
\hline AD6 & 78 & $\mathrm{M}$ & 23 & C & IV & No LB disease \\
\hline AD7 & 85 & $\mathrm{~F}$ & 14.7 & $\mathrm{C}$ & V & No LB disease \\
\hline AD8 & 71 & $\mathrm{M}$ & 10 & $\mathrm{C}$ & II & No LB disease \\
\hline AD9 & 79 & $\mathrm{M}$ & 31.5 & $\mathrm{C}$ & V & No LB disease \\
\hline AD10 & 77 & $\mathrm{~F}$ & 32 & C & VI & No LB disease \\
\hline Mean & 79.3 & & 18.3 & & & \\
\hline SEM & 2.9 & & 2.9 & & & \\
\hline \multicolumn{7}{|c|}{$\operatorname{DLB}(n=8)$} \\
\hline DLB1 & 76 & M & 21.75 & B & I & Limbic DLB \\
\hline DLB2 & 85 & $\mathrm{~F}$ & 26.5 & $B$ & I & Limbic DLB \\
\hline DLB3 & 77 & $\mathrm{~F}$ & 19.5 & $A$ & i & Neocortical DLB \\
\hline DLB4 & 81 & $\mathrm{~F}$ & 18 & $A$ & I & Diffuse DLB \\
\hline DLB5 & 69 & M & 9.5 & A & I & Diffuse DLB \\
\hline DLB6 & 70 & $\mathrm{M}$ & 21 & $A$ & i & Limbic DLB \\
\hline DLB7 & 78 & $\mathrm{~F}$ & 16 & 0 & 0 & Neocortical DLB \\
\hline DLB8 & 89 & $\mathrm{M}$ & 24.5 & $A$ & I & Neocortical DLB \\
\hline Mean & 79.3 & & 18.3 & & & \\
\hline SEM & 2.9 & & 2.9 & & & \\
\hline
\end{tabular}

C indicates control; AD, Alzheimer disease; DLB, Dementia with Lewy bodies; M, male; F, female; PMI, postmortem interval.

${ }^{*} \mathrm{~A}, \mathrm{~B}$, and $\mathrm{C}$, Braak and Braak's classification of $\mathrm{AD}$ stages depending on amyloid plaques.

${ }^{\dagger} \mathrm{O}-\mathrm{VI}$, Braak and Braak's classification of AD stages depending on the distribution and amount of neurofibrillary tangles.

To assess AlF-immunoreactivity (AlF-ir) in relation to amyloid plaques and NFTs, double immunostainings were performed by combining antibodies against AlF and $A \beta$, or against AIF and PHF-tau, respectively. Sections were first incubated with anti-human $A \beta$ antibody $(1: 200)$ or anti-PHF-tau antibody $(1: 50)$ at $4^{\circ} \mathrm{C}$ overnight, and the staining was visualized with $D A B$ as described above. Subsequently, sections were incubated with antiAlFantibody $(1: 1000)$ at $4^{\circ} \mathrm{C}$ overnight. Finally, the immunoreactivity was visualized with the second chromogen Vector SG substrate kit (Vector Laboratories). Omission or pre-adsorbing the anti-AIF antibody with its antigenic peptide (KDGEQHEDLNEVAKLFNIHED) (Sigma) resulted in a complete absence of staining (not shown).

\section{Quantification of AIF-Immunoreactive Neurons in Hippocampus and Temporal Cortex}

AlF-immunoreactive neurons were quantified using the SigmaScan image analysis software (SPSS, Chicago, IL). Images were captured using a digital camera (SPOT, Diagnostic Instruments, Sterling Heights, MI) linked to a Nikon Eclipse 800 Microscope (Tokyo, Japan). Semi- 
quantitative analyses of AIF immunostaining were performed by W.Y. in a blind fashion and were based on the following scoring criteria ${ }^{31,32}$ : A score of 0 was assigned to samples in which AIF expression was undetectable, whereas 1, 2, and 3 were assigned to samples with low, moderate, and strong immunostaining, respectively. For AlF immunostaining extent, $0,1,2,3$, and 4 was assigned to samples as 0 to $5 \%, 6$ to $25 \%, 26$ to $50 \%, 51 \%$ to $75 \%$, and $76 \%$ to $100 \%$ of the neuronal population, respectively. To provide a global score for each case, the results obtained with both scales were multiplied, yielding a single scale ranging from 0 to 16 . To calculate the percentage of AlF-immunoreactive neuronal nuclei in each brain region, their number was expressed as a fraction of the total number of AlF-immunoreactive neurons. For each subject, ten fields from five consecutive sections were analyzed in each brain region. The PMI for the samples used in this study ranged from 7.5 to 32 hours (mean $18.3 \pm 2.9$ hours) and was longer than 30 hours in three cases. To ascertain that the observed changes in AIF distribution were not attributable to the longer PMI in these three cases, we studied the effects of different $\mathrm{PMI}$ on the distribution of AIF in AD, DLB, and control brains. No significant correlation between the PMI and AlF-ir (see supplemental Figure 2 at http://ajp.amjpathol.org) or the PMI and altered AIF distribution (see supplemental Figure 3 at $h$ ttp://ajp.amjpathol.org) were observed in these brain tissues.

\section{Nuclear Fractionation and Western Blot Analysis}

Nuclear extracts were prepared with the NXTRACT CelLytic nuclear extraction kit (Sigma) according to the manufacturer's instructions. The purity of the nuclear extracts was evaluated with a rabbit polyclonal anti-GAPDH antibody, a specific cytosolic marker. Thereafter, $10 \mu \mathrm{g}$ nuclear protein obtained by biochemical fractionation from $A D$ and control brains was seperated on $4 \%$ to $20 \%$ Tris-Glycine gels (Invitrogen) and transferred to nitrocellulose membranes. Membranes were blocked with 5\% milk and incubated with anti-AIF antibody (1:3000) overnight at $4^{\circ} \mathrm{C}$. Membranes were then incubated with HRPconjugated secondary antibody (Santa Cruz Biotechology) for 1 hour at room temperature and processed with the ECL Plus chemiluminescence system (Fisher Canada). Band density was quantified by densitometric analysis with the NIH Image public domain software (http://rsb.info.nih. gov/nih-image). Values of the band intensities were normalized with those of $\beta$-actin as internal standards.

\section{Immunoprecipitation}

Immunoprecipitation was performed as described earlier. ${ }^{33}$ Briefly, cytoplasmic fractions were prepared from the temporal cortex and hippocampus of $A D$ and control brains and $800 \mu \mathrm{g}$ cytoplasmic protein was used for immunoprecipitation. The lysates were immunoprecipitated with anti-AIF antibody (10 $\mu \mathrm{g}$, Sigma) and then precipitated overnight with protein $G$ agarose beads at $4^{\circ} \mathrm{C}$. Agarose-conjugated rabbit IgG was used as nega- tive control. Samples were rinsed several times and then resuspended in loading buffer. Immunoprecipitated proteins were separated on $4 \%$ to $20 \%$ Tris-Glycine gels and submitted to Western blotting with the anti-PHF-tau antibody. The immunoreactivity was revealed by enhanced chemiluminescence.

\section{Statistical Analysis}

Statistical analysis was conducted with the Graph Pad Prism (GraphPad software, San Diego, CA). The KruskalWallis test was used to assess the difference of AIF immunoreactivity and one-way analysis of variance was used to assess the differences in numbers of AlF-ir neuronal nuclei among AD, DLB, and age-matched controls. The correlation between nuclear AIF immunoreactivity and Braak stage or $\mathrm{PMI}$ was determined with the correlation $Z$ test. Differences and correlations were considered statistically significant when $P$ values were less than 0.05 .

\section{Results}

Neuronal AlF-ir is Increased in the Hippocampus and Neocortex of $A D$ Brain

Immunocytochemical staining in $\mathrm{AD}, \mathrm{DLB}$, and control brains revealed that AIF-immunoreactive cells were dis-

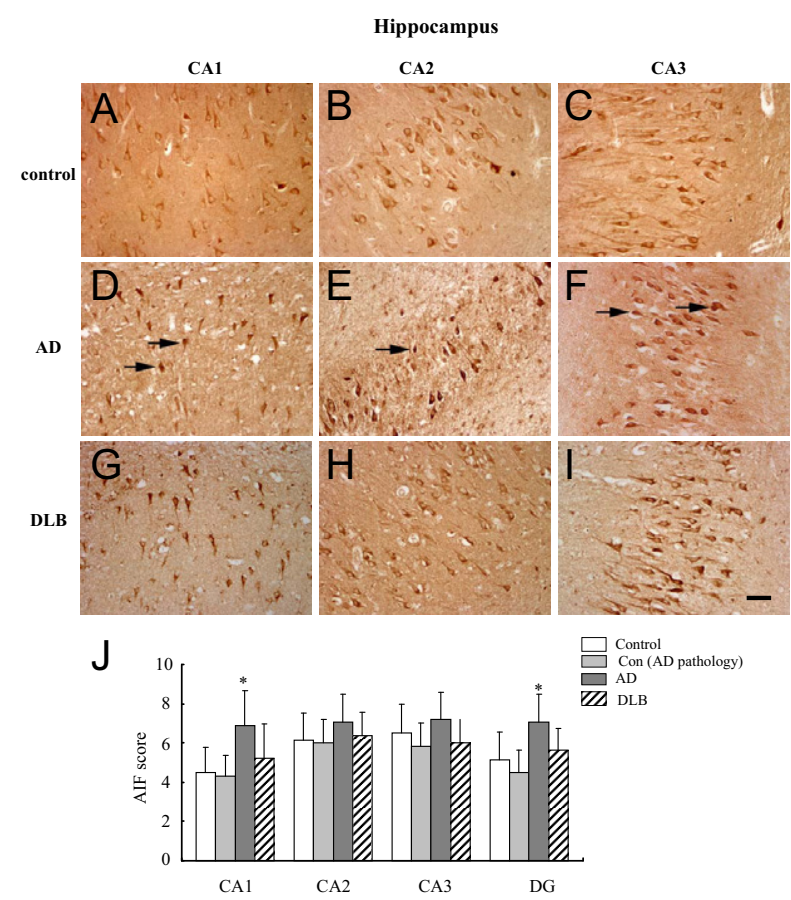

Figure 1. AIF immunoreactivity (AIF-ir) in the hippocampus of AD, DLB, control with AD pathology, and control brains. A-I: Immunostaining demonstrated that AIF was mainly expressed in neurons. AIF-ir neurons were observed in CA1 $(\mathbf{A}, \mathbf{D}$, and $\mathbf{G}), \mathrm{CA} 2(\mathbf{B}, \mathbf{E}$, and $\mathbf{H})$ and CA3 $(\mathbf{C}, \mathbf{F}$, and $\mathbf{I})$ of the hippocampus in control, AD, and DLB brains. Scale bar $=50 \mu \mathrm{m}$. $\mathbf{J}$ : Semiquantitative evaluation of AIF expression in CA1, CA2, CA3, and DG of the hippocampus in $\mathrm{AD}(n=10), \mathrm{DLB}(n=8)$, control with AD pathology $(n=8)$, and control brains $(n=11)$. ${ }^{*} P<0.05$ as compared with agematched control group using Kruskal-Wallis test. 
Entorhinal cortex

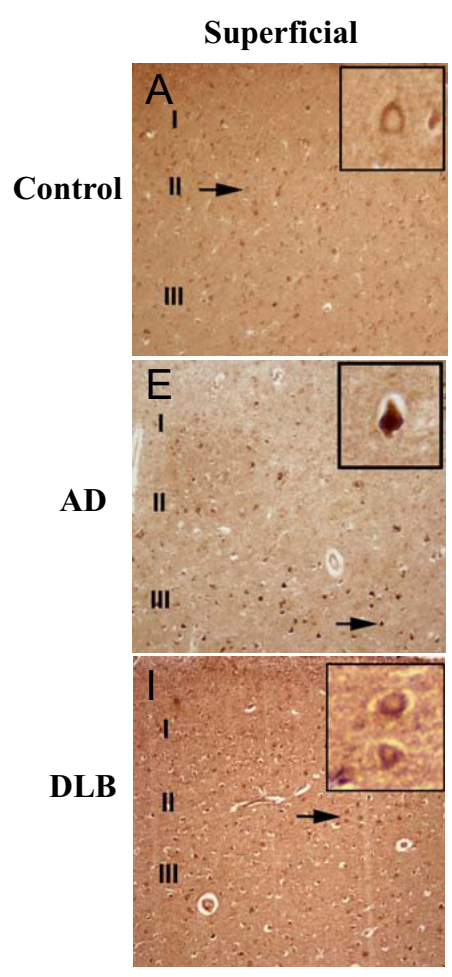

M

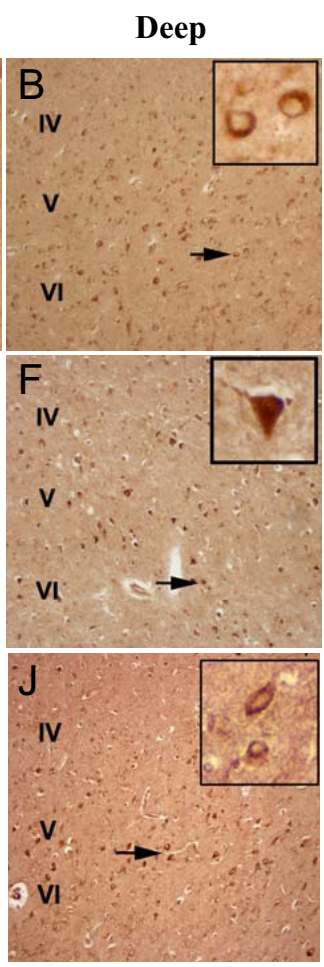

$\mathrm{N}$

\section{Temporal cortex}
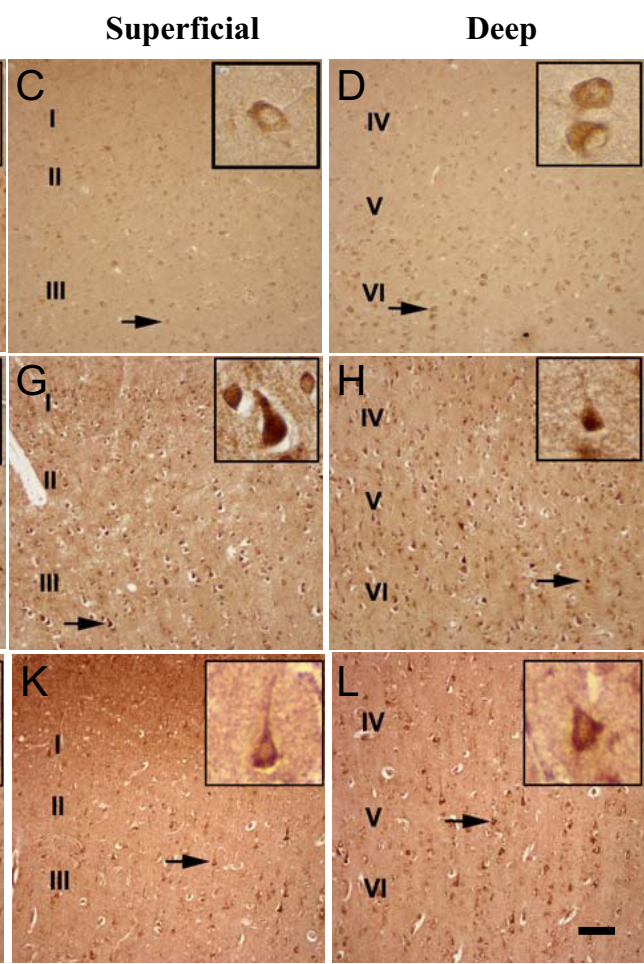

$\square$ Control

Con (AD pathology) AD

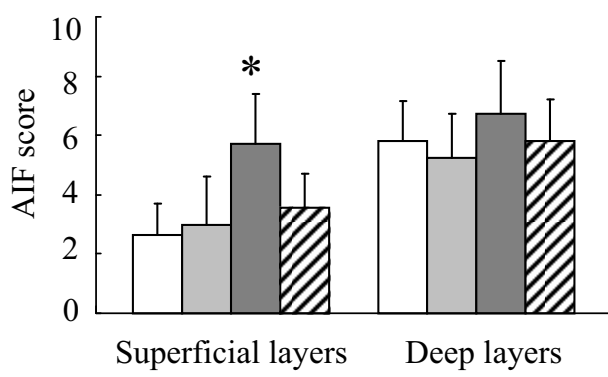

Entorhinal cortex

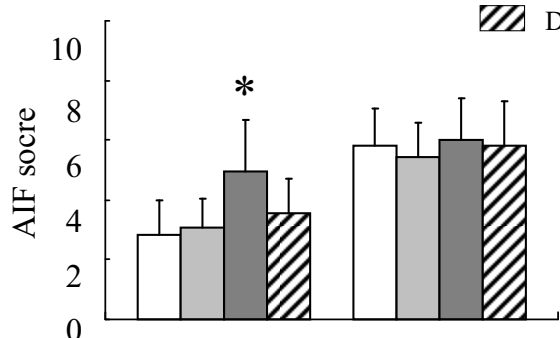

Superficial layers Deep layers

Temporal cortex

Figure 2. AIF immunoreactivity (AIF-ir) in the entorhinal and temporal cortices of AD, DLB, control with AD pathology, and control brains. A-L: Immunostaining shows that AIF (brown) was mainly expressed in neurons. Arrows indicate the cytoplasm labeling of AIF in control (A-D), DLB (I-L), as well as the nuclear labeling of AIF in AD ( $\mathbf{E}-\mathbf{H})$ brains. Insets show higher magnification of neurons indicated by the arrows. Scale bar: $100 \mu \mathrm{m}(\mathbf{A}-\mathbf{L})$. Semiquantitative evaluation of AIF expression in entorhinal $(\mathbf{M})$ and temporal cortices $(\mathbf{N})$ in $\mathrm{AD}(n=10)$, DLB $(n=8)$, control with $\mathrm{AD}$ pathology $(n=8)$, as well as control brains $(n=$ 11). ${ }^{*} P<0.05$ as compared with age-matched control group using Kruskal-Wallis test.

tributed in all fields of the hippocampus (CA1, CA2, CA3, and dentate gyrus [DG]), entorhinal cortex, and medial gyrus of the temporal cortex with marked subregional patterns. In the hippocampus, AlF- immunoreactive cells in the pyramidal layer of CA1, CA2, and CA3 fields were abundant and intensely labeled (Figure 1, A-I), whereas AIF-ir was mainly enriched in pyramidal layers (III \& V) (Figure 2, A-L) of the entorhinal and temporal cortices. Overall however, the deep (IV-VI) cortical layers displayed stronger AIF-ir than superficial ones (I-III; Figure 2, $\mathrm{M}$ and $\mathrm{N}$ ). At the cellular level, AIF immunoreactivity was exclusively observed in neurons.

A significant increase in neuronal AlF-ir was observed in the CA1, DG (Figure 1J) as well as in the superficial layers of entorhinal and temporal cortices in AD compared with age-matched controls (Figure 2, M and N). No significant difference in neuronal AlF-ir was observed between DLB and controls (Figures $1 \mathrm{~J}$ and 2, $\mathrm{M}$ and $\mathrm{N}$ ).

\section{Nuclear AlF-ir is Increased in the Hippocampus and Neocortex of AD Brains}

The nuclear translocation of AIF can induce apoptotic neuronal death in a caspase-independent manner. ${ }^{15,22}$ We thus determined the proportion of neurons displaying a nuclear localization of AIF versus total AIF- immunoreactive neurons. In AD, DLB, and age-matched control 


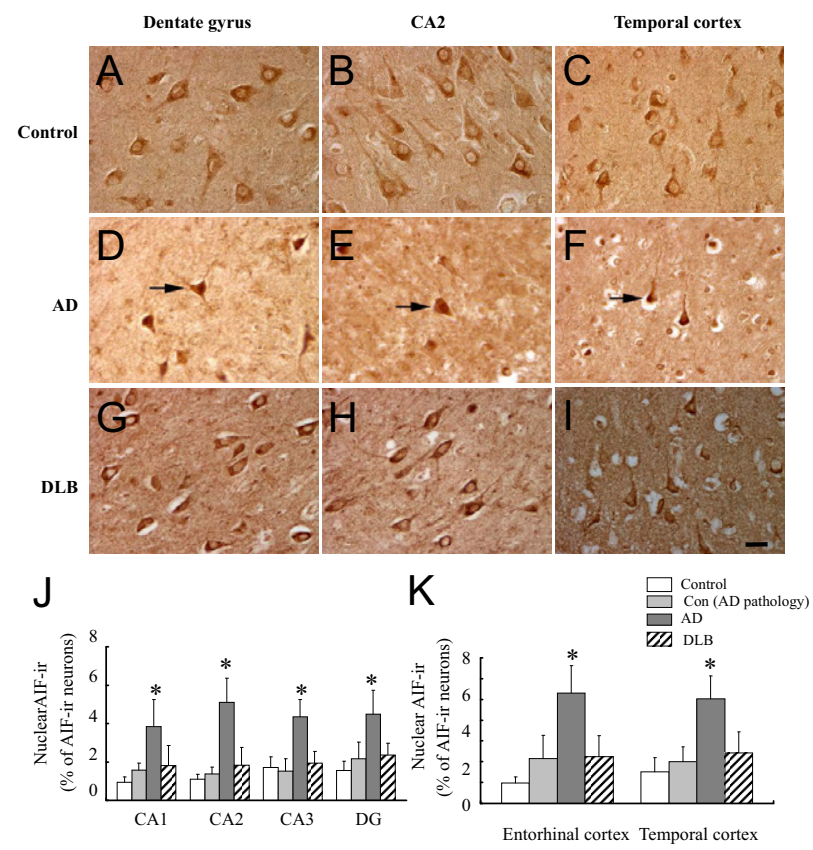

Figure 3. Subcellular localization of AIF in the hippocampus, entorhinal, and temporal cortices of AD, DLB, control with AD pathology, as well as control brains. A-I: AIF-ir was mainly expressed in the cytoplasm of neurons. Some nuclear labeling were detected in dental gyrus (arrow, D), CA2 (arrow, E), and temporal cortex (arrow, F) of AD brains, but not in control (A-C) and DLB $(\mathbf{G}-\mathbf{I})$ brains. Scale bar $=25 \mu \mathrm{m}$. J-K: Nuclear AIF-ir suggesting that AIF was translocated to the nucleus was mainly seen in the pyramidal layers of these brain regions. Quantitative analysis indicated a significant increase in the nuclear localization of AIF in the hippocampus, entorhinal, and temporal cortices of $\mathrm{AD}(n=10)$ but not $\operatorname{DLB}(n=8)$ or control with AD pathology $(n=8)$ compared with age-matched control brains $(n=11) .{ }^{*} P<0.01$ as compared with age-matched controls using one-way analysis of variance.

brains, the majority of neurons displayed a clear nuclear exclusion of AIF labeling while some neurons showed nuclear staining (Figure 3A-I). AlF- immunoreactive nuclei were localized mainly in the pyramidal layers (Figure $3, A-I)$. Significant increase in nuclear translocation of AIF was detected in the pyramidal layers of the hippocampus (CA1, CA2, CA3, and DG) and entorhinal and temporal cortices in $A D$ compared with age-matched controls (Figure $3, \mathrm{~J}$ and $\mathrm{K}$ ). No difference in AIF nuclear translocation was detected between DLB and control subjects in any of the brain regions under study (Figure 3, J and K). These findings were further confirmed by Western blotting quantification of AIF protein levels in nuclear fractions prepared from the same brain regions (hippocampus and temporal cortices) of $\mathrm{AD}$ and control brains ( $n=6$ per group). Immunoreactive signals for cleaved AIF and $\beta$-actin in nuclear protein extracts appeared at 57 and $42 \mathrm{kDa}$, respectively. The amounts of AIF proteins in the nuclear fraction of the hippocampus and temporal cortex were significantly increased in AD versus control brains (Figure 4, A and B).

\section{Similar Distribution of Neuronal and Nuclear AlF-ir in the Hippocampus and Neocortex of Controls and Controls with $A D$ Lesions}

It has been postulated that AD pathology begins many years before the onset of clinical symptomatology, result-
A

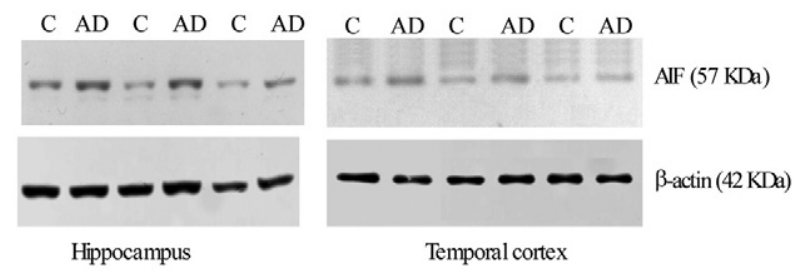

B

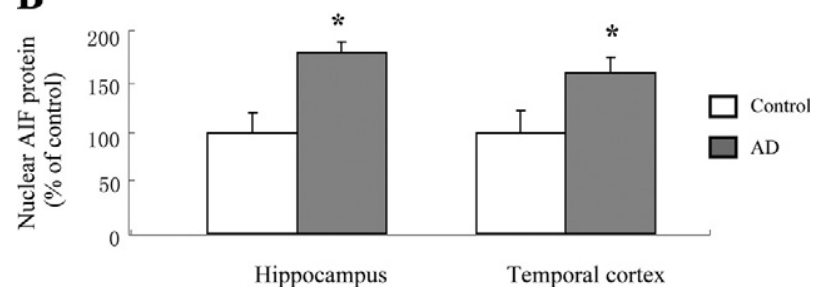

Figure 4. The AIF protein $(57 \mathrm{kDa})$ in the nuclear fraction is increased in $\mathrm{AD}$ $(n=6)$ hippocampus and temporal cortex compared with age-matched control tissues $(n=6)$. A: Representative Western blot analyses of AIF protein in the nuclear fractions from AD and control brains. Samples (10 $\mu \mathrm{g}$ nuclear protein) were resolved by eletrophoresis on $4 \%$ to $20 \%$ Tris-Glycine gels, transferred onto nitrocellulose membrane, and probed with rabbit AIF antiserum. B: Quantitative Western blot analysis of the AIF protein $(57 \mathrm{kDa})$ levels in the hippocampus and temporal cortex of $\mathrm{AD}$ and control subjects. Each sample was loaded in triplicate. Each bar represents a mean of six AD and six control samples and presented as a percentage of control samples. ${ }^{*} P<0.01$ as compared with age-matched controls using unpaired Student $t$ test.

ing in a long prodromal phase of $A D .^{34,35}$ We therefore explored whether the changes in the distribution of AIF-ir occur in the control brains with signs of $A D$ pathology (below threshold for AD diagnosis). These cases were considered as representative of the prodromal stage of AD (Table 1). No significant difference in the distribution of either neuronal AIF-ir or nuclear AIF-ir was detected in the hippocampus, entorhinal as well as temporal cortices of control brains with AD pathology when compared with the control brains without $A D$ lesions (Figures 1J, 2, M and $\mathrm{N}$, and $3, \mathrm{~J}$ and $\mathrm{K}$ ).

\section{Nuclear AlF-ir in AD Brain and Braak Stage are Correlated}

To assess the relative changes in the nuclear localization of AIF with respect to disease severity, nuclear AIF-ir in AD samples was assessed in relation to Braak stage. ${ }^{26}$ This analysis revealed a significantly positive correlation between nuclear AIF-ir and Braak stage in the CA1, as well as entorhinal and temporal cortices, but not in CA2, CA3, and DG of the hippocampus (Figure 5, A-F).

\section{AIF Immunoreactivity is Colocalized with NFTs in AD Brains}

In the course of the experiments described above, we observed a striking feature of AIF-ir in AD brains, which consisted of intraneuronal 'flame-like' inclusions, similar to NFTs (Figure 6, A-C). We therefore assessed the relationship between AIF and NFTs by performing doublelabeling experiments using antibodies against the NFT 
A

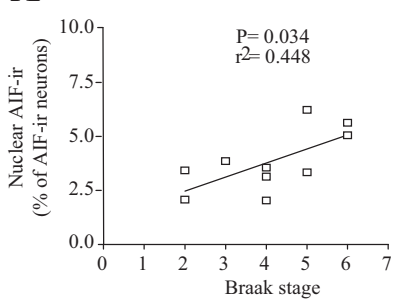

$\mathrm{CA} 3$
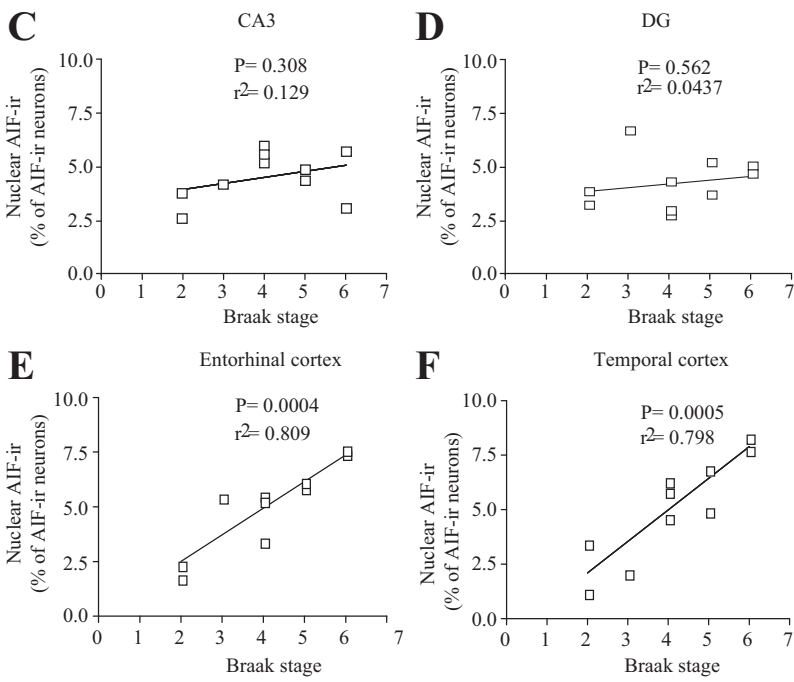

Figure 5. Significant positive correlation was seen between the nuclear translocation of AIF and Braak stage in CA1 (A), entorhinal $(\mathbf{E})$, and temporal (F) cortices, but not in CA2 (B), CA3 (C) and DG (D), in the AD brain $(n=10)$.

marker (AT8) together with the AIF antibody. Colocalization was evident in neurons with clear NFT features in AD brains (Figure 6, D-F). In particular, the colocalization was most pronounced in the CA1, entorhinal, and medial gyrus of temporal cortices, where a large proportion of neurons with NFT morphology were stained with AIF and AT8 antibodies. In the DG, CA3, and CA2 regions, a

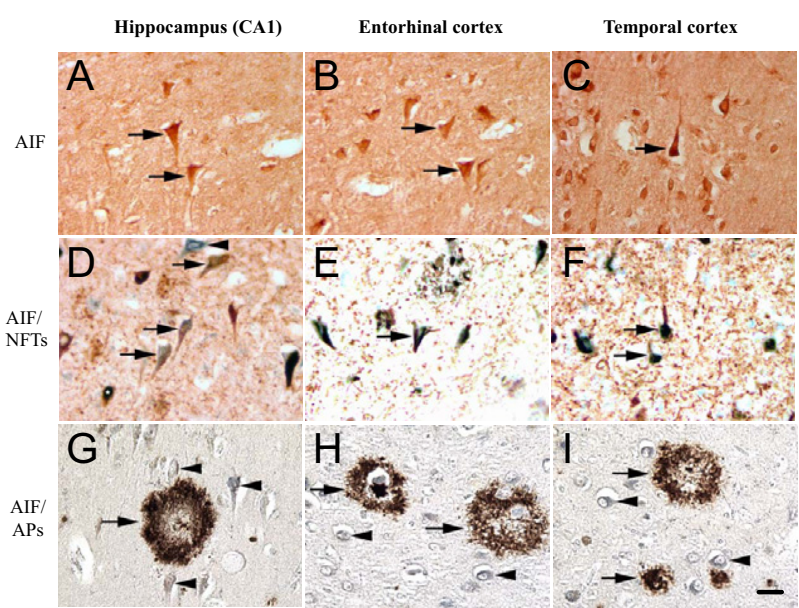

Figure 6. Colocalization of AIF-ir with NFTs but not with amyloid plaques in AD brains. A-C: AIF-ir neurons in the AD brain show 'flame-like' inclusions, consistent with tangle formation (arrows). D-F: Double immunolabeling shows a colocalization of NFTs (brown) and AIF-ir (green) in AD brain (arrows) Arrowheads indicate AIF-ir neurons. G-I: No colocalization of AIF-ir neurons (green, indicated by arrowheads) was observed in neuritic or diffused plaques (brown, indicated by arrows). Scale bar $=25 \mu \mathrm{m}$.
A
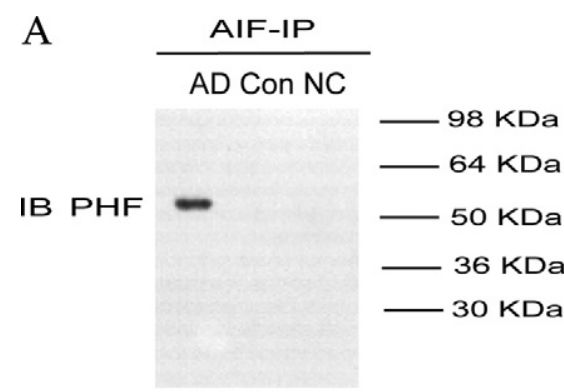

B

PHF-IP

AD Con NC

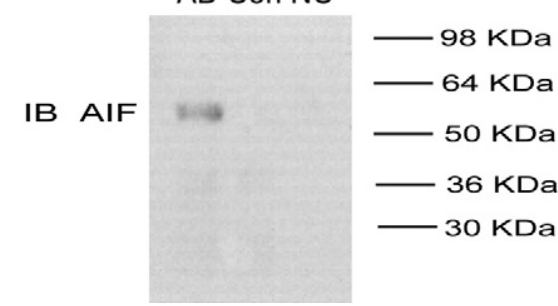

Figure 7. AIF is co-assembled with NFTs in the hippocampus of AD brain. A: Immunoprecipitation in the hippocampus extracts of $\mathrm{AD}(n=10)$ and control brains $(n=10)$ with anti-AIF antibody and then subjected to SDSPAGE, electroblotted, and probed with anti-PHF-tau antibody. B: Immunoprecipitation in the hippocampus extracts of $\mathrm{AD}$ and control brains with anti-PHF-tau antibody and then subjected to SDS-PAGE, electroblotted, and probed with anti-AIF antibody. The results show that the AIF is co-associated with the NFTs in the hippocampus of AD brain. Results shown were obtained from three experiments. IP indicates immunoprecipitate; IB, immunoblotting; NC, negative control.

smaller proportion of neurons were double-labeled (not shown).

To determine the relationship between AIF immunoreactivity and amyloid deposition, double-immunolabeling with anti-AIF and anti- $\beta$ amyloid antibodies was performed. In no case was colocalization of AIF-ir and diffused or neuritic plaques observed (Figure 6, G-I).

\section{AIF and PHF-tau Constituents of NFT Coprecipitate in Control and AD Brains}

To further explore the observed colocalization of AIF and NFTs, we next performed immunoprecipitation assays to establish whether AIF directly interacts with the components of NFTs. Immunoprecipatation assays using a polyclonal anti-AIF antibody followed by immunoblotting with monoclonal anti-PHF-tau antibody demonstrated an association between AIF and NFTs in neurons from hippocampus and temporal cortices in $A D$ brains (Figure 7A). Similarly, reciprocal immunoblotting assays with AIF antibody followed by immunoprecipitation with PHF-tau antibody confirmed the association between AIF and NFTs in AD brains (Figure 7B). In contrast, association between AIF and NFTs was not detected in the same brain regions of control subjects.

\section{Discussion}

The present study was undertaken to investigate and compare the regional, cellular, and subcellular distribu- 
tions of AIF in control, $A D$, and DLB brains, as well as the possible association of this protein with key neuropathological AD features (amyloid plaques and NFTs). The major findings are that (1) an increased neuronal AIF-ir was observed in subregions of the hippocampus and entorhinal cortex of AD but not DLB subjects, (2) AIF nuclear translocation (AlF-immunoreactive nuclei) in neurons was significantly more widespread in $A D$ than in control and DLB brains, and (3) AIF-ir was colocalized with NFTs, but not with amyloid plaques in AD brains. To our knowledge, this study provides the first demonstrations of increased nuclear translocation of AIF and its colocalization with NFTs in the AD brain.

The increase in neuronal AIF-ir in the hippocampus and entorhinal cortex in AD brains may represent a compensatory mechanism against AD-related neuropathological changes, such as increased oxidative stress and free radical-mediated molecular damage. ${ }^{36-38}$ AIF may act as a reactive oxygen species (ROS) scavenger, as it has been shown that cerebellar granule cells from mutant mice with decreased AIF expression are more sensitive to peroxide-induced cell death, but may be rescued by the overexpression of AIF in wild-types. ${ }^{19,39}$ Accordingly, the apparent increased expression of AIF observed here may act to counteract increased oxidative stress occurring in the $A D$ brain. ${ }^{40}$ The unscheduled re-entry into the cell cycle has been suggested to play an early role in the pathogenesis of $A D .{ }^{41}$ The dysregulation of the cell cycle in neurons has been associated with the AD-related pathology and induction of neuronal cell death. ${ }^{42,43}$ Interestingly, this abnormal cell cycle re-entry is linked to AD-related oxidative stress. ${ }^{44}$ Thus, an increase in AlF-ir might represent a defense mechanism against abnormal cell cycle re-entry in AD.

Although AlF has an important protective physiological role in mitochondria, ${ }^{15,18}$ its translocation to the nucleus leads to cell death in a caspase-independent manner. ${ }^{15,22}$ In the present study, we report an increase in the expression of the nuclear AIF form $(57 \mathrm{kDa})$ in both hippocampus and temporal cortex (immunoblotting) and more widespread nuclear localization of AIF in the AD hippocampus and neocortex (immunohistochemistry). The magnitude of difference in nuclear AlF-ir measured by immunoblotting was not as important as that predicted by immunohistochemistry. This is possibly related to the high noise-to-signal ratio in the nuclear fraction isolated by biochemical methods. Indeed, biochemical isolation of nuclear fraction involves not only neurons displaying nuclear translocation of AIF but also glial cells with undetectable AIF levels, as indicated by our immunocytochemical data.

Interestingly, the nuclear localization of AIF was mainly observed in pyramidal layers of the hippocampus and temporal cortex. In agreement, previous studies have reported the neuronal losses in these regions in $A D$, with the larger pyramidal neurons in cortical laminae III and V being affected the most. ${ }^{45-47}$ Our results suggest that an AIF-mediated caspase-independent apoptotic pathway may also be involved in the cell death of these neurons and related neuronal degeneration. This would be consistent with recent data demonstrating that $A \beta$ peptides trigger mitochondrial release and nuclear translocation of AIF in primary rat cortical cultures. ${ }^{48}$ However, our results suggest a close association between AlF-ir and NFTs rather than between AIF and amyloid plaques. Because the latter are composed of large, insoluble $A \beta$ aggregates, ${ }^{49}$ our results suggest that in vivo, soluble $A \beta$ species may be more relevant for nuclear translocation of AIF in AD.

$A D$ has been postulated to begin many years before the onset of clinical symptomatology, resulting in a long prodromal phase. ${ }^{50}$ Indeed, a proportion of nondemented elderly subjects can show significant levels of $A \beta$ plaques, NFTs, and inflammation in regions typically affected by AD. ${ }^{34}$ Because no significant neuronal loss is observed in the brains of nondemented elderly compared with $A D$ subjects, the pathological alterations in the former can be defined histopathologically as the prodromal phase of $A D$. We therefore explored AlF-immunoreative cell distribution in the prodromal $A D$ brain and found no significant change between prodromal AD compared with control brains. These results suggested that changes in AlF distribution occur mainly in the later, rather than the early stage of $A D$. Further support for this hypothesis was the observed correlation between the nuclear localization of AIF in AD brains and Braak stage that reflects the progressive nature of $A D$.

The intensity of oxidative stress increases with the progression of AD pathology. ${ }^{51,52}$ The considerable capacity of AIF for free radical scavenging may be a likely event as a compensatory mechanism in our control subjects with $A D$ pathology that are below the threshold for $\mathrm{AD}$ diagnosis. ${ }^{19}$ Pioneer work by Klein and colleagues reported the consequences of increased oxidative stress regarding neuronal loss and neurodegeneration become manifest only when the expression of the endogenous AIF falls below $20 \%$ of its physiological level. ${ }^{19}$ This phenomenon implies that although AIF might be involved in the control of neuronal survival/death from prodromal to early stages of $A D$ progression, such involvement might become more apparent only at mid-to-late stages of the pathology. To explore this hypothesis, transgenic $A D$ models may provide further insight into the initial events involved in AD pathogenesis.

The present study points to a colocalization of AIF-ir and NFTs within individual neurons in AD brains. NFTs are composed of hyperphosphorylated tau protein, which initially accumulates in neurons within the entorhinal cortex and CA1 subfield of the hippocampus. ${ }^{26,53,54}$ This intracellular hyperphosphorylated tau leads to the formation of NFTs, which destabilizes the cytoskeleton network. ${ }^{55,56}$ Hyperphosphorylated tau has reduced binding affinity for microtubules, leading to the depolymerization of microtubules and contributing to the neuronal losses observed in AD. ${ }^{56,57}$ Recent studies have shown that tau is a cleavage substrate for activated caspases-3, -6, -8 , and -9 after apoptotic stimuli. ${ }^{4,5,7,10,58}$ The caspase cleavage of tau generates a proteolytic product that assembles more readily and extensively into pathological tau filaments.,59 The data presented here suggest that the main mediator of caspase-independent apoptotic pathway, AlF is associated with the NFT-initiated tangle 
pathology. Further investigations will be required to establish the role of AIF in tau pathology using models of AlF-overexpressing cells and "triple" transgenic AD mice expressing hyperphosphorylated pathological form of tau. ${ }^{60}$

The increased cellular AIF-ir in the AD hippocampus and entorhinal cortex seems at odds with our previous report showing that the overall level of AlF expression in frontal and temporal cortices of AD patients is lower than in age-matched controls. ${ }^{24}$ This disparity is likely related to the difference in methodological approaches: immunohistochemistry versus immunoblotting used in our present and previous studies, respectively. Indeed, immunocytochemistry allows the identification of regional and subregional differences in AIF distribution. It is likely that different brain cell populations display different levels of AIF expression and could have remained undetectable in immunoblotting experiments using tissue homogenates.

In summary, our results suggest that neuronal AIF is upregulated in the AD hippocampus and entorhinal cortex. Moreover, we report that AIF is intimately linked to NFTs. Finally, the increased nuclear localization of AIF in the AD brain suggests a possible role for AIF in caspaseindependent apoptosis and neuronal degeneration at mid-to-late stages of this neurodegenerative disorder.

\section{Acknowledgments}

We thank Danielle Cécyre (Quebec Brain Bank-QBB) for her assistance (The QBB is supported by the Douglas Institute Foundation and FRSQ). We also greatly appreciate the assistance of Dr. Jean-Guy Chabot in microscopic imaging and Mira Thakur for editing and proofreading the manuscript.

\section{References}

1. Marx J: Neuroscience. New leads on the 'how' of Alzheimer's. Science 2001, 293:2192-2194

2. Mattson MP: Apoptosis in neurodegenerative disorders. Nat Rev Mol Cell Biol 2000, 1:120-129

3. LeBlanc AC: The role of apoptotic pathways in Alzheimer's disease neurodegeneration and cell death. Curr Alzheimer Res 2005, 2:389-402

4. Chung CW, Song YH, Kim IK, Yoon WJ, Ryu BR, Jo DG, Woo HN, Kwon YK, Kim HH, Gwag BJ, Mook-Jung IH, Jung YK: Proapoptotic effects of tau cleavage product generated by caspase-3. Neurobiol Dis 2001, 8:162-172

5. Gamblin TC, Chen F, Zambrano A, Abraha A, Lagalwar S, Guillozet AL, Lu M, Fu Y, Garcia-Sierra F, LaPointe N, Miller R, Berry RW, Binder LI, Cryns VL: Caspase cleavage of tau: linking amyloid and neurofibrillary tangles in Alzheimer's disease. Proc Natl Acad Sci U S A 2003, 100:10032-10037

6. Gervais FG, Xu D, Robertson GS, Vaillancourt JP, Zhu Y, Huang J, LeBlanc A, Smith D, Rigby M, Shearman MS, Clarke EE, Zheng H, Van Der Ploeg LH, Ruffolo SC, Thornberry NA, Xanthoudakis S, Zamboni RJ, Roy S, Nicholson DW: Involvement of caspases in proteolytic cleavage of Alzheimer's amyloid-beta precursor protein and amyloidogenic A beta peptide formation. Cell 1999, 97:395-406

7. Guo H, Albrecht S, Bourdeau M, Petzke T, Bergeron C, LeBlanc AC: Active caspase-6 and caspase-6-cleaved tau in neuropil threads, neuritic plaques, and neurofibrillary tangles of Alzheimer's disease. Am J Pathol 2004, 165:523-531

8. Lu DC, Rabizadeh S, Chandra S, Shayya RF, Ellerby LM, Ye X,
Salvesen GS, Koo EH, Bredesen DE: A second cytotoxic proteolytic peptide derived from amyloid beta-protein precursor. Nat Med 2000, 6:397-404

9. Rohn TT, Head E, Nesse WH, Cotman CW, Cribbs DH: Activation of caspase-8 in the Alzheimer's disease brain. Neurobiol Dis 2001, 8:1006-1016

10. Rohn TT, Rissman RA, Davis MC, Kim YE, Cotman CW, Head E: Caspase- 9 activation and caspase cleavage of tau in the Alzheimer's disease brain. Neurobiol Dis 2002, 11:341-354

11. Cregan SP, Fortin A, MacLaurin JG, Callaghan SM, Cecconi F, Yu SW, Dawson TM, Dawson VL, Park DS, Kroemer G, Slack RS: Apoptosis-inducing factor is involved in the regulation of caspase-independent neuronal cell death. J Cell Biol 2002, 158:507-517

12. Krantic S, Mechawar N, Reix S, Quirion R: Apoptosis-inducing factor: a matter of neuron life and death. Prog Neurobiol 2007, 81:179-196

13. Lankiewicz S, Marc Luetjens C, Truc Bui N, Krohn AJ, Poppe M, Cole GM, Saido TC, Prehn JH: Activation of calpain I converts excitotoxic neuron death into a caspase-independent cell death. J Biol Chem 2000, 275:17064-17071

14. Joza N, Susin SA, Daugas E, Stanford WL, Cho SK, Li CY, Sasaki T, Elia AJ, Cheng HY, Ravagnan L, Ferri KF, Zamzami N, Wakeham A, Hakem R, Yoshida H, Kong YY, Mak TW, Zuniga-Pflucker JC, Kroemer G, Penninger JM: Essential role of the mitochondrial apoptosis-inducing factor in programmed cell death. Nature 2001, 410:549-554

15. Susin SA, Lorenzo HK, Zamzami N, Marzo I, Snow BE, Brothers GM, Mangion J, Jacotot E, Costantini P, Loeffler M, Larochette N, Goodlett DR, Aebersold R, Siderovski DP, Penninger JM, Kroemer G: Molecular characterization of mitochondrial apoptosis-inducing factor. Nature 1999, 397:441-446

16. Wang H, Yu SW, Koh DW, Lew J, Coombs C, Bowers W, Federoff HJ, Poirier GG, Dawson TM, Dawson VL: Apoptosis-inducing factor substitutes for caspase executioners in NMDA-triggered excitotoxic neuronal death. J Neurosci 2004, 24:10963-10973

17. Otera H, Ohsakaya S, Nagaura Z, Ishihara N, Mihara K: Export of mitochondrial AIF in response to proapoptotic stimuli depends on processing at the intermembrane space. EMBO J 2005, 24:1375-1386

18. Vahsen N, Cande C, Briere JJ, Benit P, Joza N, Larochette N Mastroberardino PG, Pequignot MO, Casares N, Lazar V, Feraud O, Debili N, Wissing S, Engelhardt S, Madeo F, Piacentini M, Penninger JM, Schagger H, Rustin P, Kroemer G: AlF deficiency compromises oxidative phosphorylation. EMBO J 2004, 23:4679-4689

19. Klein JA, Longo-Guess CM, Rossmann MP, Seburn KL, Hurd RE, Frankel WN, Bronson RT, Ackerman SL: The harlequin mouse mutation downregulates apoptosis-inducing factor. Nature 2002, 419:367-374

20. Polster BM, Basanez G, Etxebarria A, Hardwick JM, Nicholls DG: Calpain I induces cleavage and release of apoptosis-inducing factor from isolated mitochondria. J Biol Chem 2005, 280:6447-6454

21. Yuste VJ, Moubarak RS, Delettre C, Bras M, Sancho P, Robert N, d'Alayer J, Susin SA: Cysteine protease inhibition prevents mitochondrial apoptosis-inducing factor (AIF) release. Cell Death Differ 2005, 12:1445-1448

22. Daugas E, Susin SA, Zamzami N, Ferri KF, Irinopoulou T, Larochette N, Prevost MC, Leber B, Andrews D, Penninger J, Kroemer G: Mitochondrio-nuclear translocation of AIF in apoptosis and necrosis. FASEB J 2000, 14:729-739

23. Zhang X, Chen J, Graham SH, Du L, Kochanek PM, Draviam R, Guo F, Nathaniel PD, Szabo C, Watkins SC, Clark RS: Intranuclear localization of apoptosis-inducing factor (AIF) and large scale DNA fragmentation after traumatic brain injury in rats and in neuronal cultures exposed to peroxynitrite. J Neurochem 2002, 82:181-191

24. Reix S, Mechawar N, Susin SA, Quirion R, Krantic S: Expression of cortical and hippocampal apoptosis-inducing factor (AIF) in aging and Alzheimer's disease. Neurobiol Aging 2007, 28:351-356

25. Harding AJ, Lakay B, Halliday GM: Selective hippocampal neuron loss in dementia with Lewy bodies. Ann Neurol 2002, 51:125-128

26. Braak $H$, Braak E: Neuropathological stageing of Alzheimer-related changes. Acta Neuropathol 1991, 82:239-259

27. Mirra SS, Heyman A, McKeel D, Sumi SM, Crain BJ, Brownlee LM, Vogel FS, Hughes JP, van Belle G, Berg L: The Consortium to Establish a Registry for Alzheimer's Disease (CERAD). Part II: Standardization of the neuropathologic assessment of Alzheimer's disease. Neurology 1991, 41:479-486 
28. McKeith IG, Galasko D, Kosaka K, Perry EK, Dickson DW, Hansen LA, Salmon DP, Lowe J, Mirra SS, Byrne EJ, Lennox G, Quinn NP, Edwardson JA, Ince PG, Bergeron C, Burns A, Miller BL, Lovestone S, Collerton D, Jansen EN, Ballard C, de Vos RA, Wilcock GK, Jellinger $\mathrm{KA}$, Perry $\mathrm{RH}$ : Consensus guidelines for the clinical and pathologic diagnosis of dementia with Lewy bodies (DLB): report of the consortium on DLB international workshop. Neurology 1996, 47:1113-1124

29. McKeith I, Mintzer J, Aarsland D, Burn D, Chiu H, Cohen-Mansfield J, Dickson D, Dubois B, Duda JE, Feldman H, Gauthier S, Halliday G, Lawlor B, Lippa C, Lopez OL, Carlos Machado J, O'Brien J, Playfer J, Reid W: Dementia with Lewy bodies. Lancet Neurol 2004, 3:19-28

30. Yu WF, Guan ZZ, Bogdanovic N, Nordberg A: High selective expression of alpha7 nicotinic receptors on astrocytes in the brains of patients with sporadic Alzheimer's disease and patients carrying Swedish APP 670/671 mutation: a possible association with neuritic plaques. Exp Neurol 2005, 192:215-225

31. Boddaert J, Kinugawa K, Lambert JC, Boukhtouche F, Zoll J, Merval R, Blanc-Brude O, Mann D, Berr C, Vilar J, Garabedian B, Journiac N, Charue D, Silvestre JS, Duyckaerts C, Amouyel P, Mariani J, Tedgui A, Mallat Z: Evidence of a role for lactadherin in Alzheimer's disease. Am J Pathol 2007, 170:921-929

32. Herfs M, Hubert P, Kholod N, Caberg JH, Gilles C, Berx G, Savagner $P$, Boniver J, Delvenne P: Transforming growth factor-beta1-mediated Slug and Snail transcription factor up-regulation reduces the density of Langerhans cells in epithelial metaplasia by affecting E-cadherin expression. Am J Pathol 2008, 172:1391-1402

33. Yu WF, Guan ZZ, Nordberg A: Postnatal upregulation of alpha4 and alpha3 nicotinic receptor subunits in the brain of alpha7 nicotinic receptor-deficient mice. Neuroscience 2007, 146:1618-1628

34. Morris JC, Price AL: Pathologic correlates of nondemented aging, mild cognitive impairment, and early-stage Alzheimer's disease. J Mol Neurosci 2001, 17:101-118

35. Hulette CM, Welsh-Bohmer KA, Murray MG, Saunders AM, Mash DC, McIntyre LM: Neuropathological and neuropsychological changes in "normal" aging: evidence for preclinical Alzheimer disease in cognitively normal individuals. J Neuropathol Exp Neurol 1998, 57:1168-1174

36. Mattson MP: Pathways towards and away from Alzheimer's disease. Nature 2004, 430:631-639

37. Smith MA, Perry G, Richey PL, Sayre LM, Anderson VE, Beal MF, Kowall $\mathrm{N}$ : Oxidative damage in Alzheimer's. Nature 1996, 382:120-121

38. Williams TI, Lynn BC, Markesbery WR, Lovell MA: Increased levels of 4-hydroxynonenal and acrolein, neurotoxic markers of lipid peroxidation, in the brain in Mild Cognitive Impairment and early Alzheimer's disease. Neurobiol Aging 2006, 27:1094-1099

39. Lipton SA, Bossy-Wetzel E: Dueling activities of AIF in cell death versus survival: dNA binding and redox activity. Cell 2002, 111:147-150

40. Good PF, Werner P, Hsu A, Olanow CW, Perl DP: Evidence of neuronal oxidative damage in Alzheimer's disease. Am J Pathol 1996, 149:21-28

41. Zhu X, Raina AK, Perry G, Smith MA: Alzheimer's disease: the two-hit hypothesis. Lancet Neurol 2004, 3:219-226

42. Giovanni A, Wirtz-Brugger F, Keramaris E, Slack R, Park DS: Involvement of cell cycle elements, cyclin-dependent kinases, pRb, and E2F $x$ DP, in B-amyloid-induced neuronal death. J Biol Chem 1999, 274:19011-19016
43. Park DS, Obeidat A, Giovanni A, Greene LA: Cell cycle regulators in neuronal death evoked by excitotoxic stress: implications for neurodegeneration and its treatment. Neurobiol Aging 2000, 21:771-781

44. Zhu X, Lee HG, Perry G, Smith MA: Alzheimer disease, the two-hit hypothesis: an update. Biochim Biophys Acta 2007, 1772:494-502

45. Gomez-Isla T, Price JL, McKeel DW, Jr., Morris JC, Growdon JH, Hyman BT: Profound loss of layer II entorhinal cortex neurons occurs in very mild Alzheimer's disease. J Neurosci 1996, 16:4491-4500

46. Morrison JH: Differential vulnerability, connectivity, and cell typology Neurobiol Aging 1993, 14:51-54; discussion 55-56

47. West MJ, Coleman PD, Flood DG, Troncoso JC: Differences in the pattern of hippocampal neuronal loss in normal ageing and Alzheimer's disease. Lancet 1994, 344:769-772

48. Movsesyan VA, Stoica BA, Faden Al: MGLuR5 activation reduces beta-amyloid-induced cell death in primary neuronal cultures and attenuates translocation of cytochrome $\mathrm{c}$ and apoptosis-inducing factor. J Neurochem 2004, 89:1528-1536

49. Hardy J, Selkoe DJ: The amyloid hypothesis of Alzheimer's disease: progress and problems on the road to therapeutics. Science 2002, 297:353-356

50. Kern A, Behl C: The unsolved relationship of brain aging and late-onset Alzheimer disease, Biochim Biophys Acta 2009, 1790:1124-1132

51. Reddy PH: Amyloid precursor protein-mediated free radicals and oxidative damage: implications for the development and progression of Alzheimer's disease. J Neurochem 2006, 96:1-13

52. Nunomura A, Castellani RJ, Zhu X, Moreira PI, Perry G, Smith MA: Involvement of oxidative stress in Alzheimer disease. J Neuropathol Exp Neurol 2006, 65:631-641

53. Grundke-lqbal I, Iqbal K, Quinlan M, Tung YC, Zaidi MS, Wisniewski HM: Microtubule-associated protein tau. A component of Alzheimer paired helical filaments. J Biol Chem 1986, 261:6084-6089

54. Wischik CM, Novak M, Edwards PC, Klug A, Tichelaar W, Crowther RA: Structural characterization of the core of the paired helical filament of Alzheimer disease. Proc Natl Acad Sci U S A 1988, 85:4884-4888

55. Alonso AC, Grundke-lqbal I, lqbal K: Alzheimer's disease hyperphosphorylated tau sequesters normal tau into tangles of filaments and disassembles microtubules. Nat Med 1996, 2:783-787

56. Bramblett GT, Goedert M, Jakes R, Merrick SE, Trojanowski JQ, Lee VM: Abnormal tau phosphorylation at Ser396 in Alzheimer's disease recapitulates development and contributes to reduced microtubule binding. Neuron 1993, 10:1089-1099

57. Biernat J, Gustke N, Drewes G, Mandelkow EM, Mandelkow E: Phosphorylation of Ser262 strongly reduces binding of tau to microtubules: distinction between PHF-like immunoreactivity and microtubule binding. Neuron 1993, 11:153-163

58. Rohn TT, Head E, Su JH, Anderson AJ, Bahr BA, Cotman CW, Cribbs DH: Correlation between caspase activation and neurofibrillary tangle formation in Alzheimer's disease. Am J Pathol 2001, 158:189-198

59. Cho JH, Johnson GV: Glycogen synthase kinase 3 beta induces caspase-cleaved tau aggregation in situ. J Biol Chem 2004, 279: $54716-54723$

60. Oddo S, Caccamo A, Shepherd JD, Murphy MP, Golde TE, Kayed R, Metherate R, Mattson MP, Akbari Y, LaFerla FM: Triple-transgenic model of Alzheimer's disease with plaques and tangles: intracellular Abeta and synaptic dysfunction. Neuron 2003, 39:409-421 